\title{
ELS TRES COMPLEXOS DE LA FILOLOGIA CLÀSSICA
}

\author{
JOAN MUT I ARBÓs \\ Universitat de les Illes Balears \\ j.mut@uib.cat
}

RESUM

L'article suposa una breu dissertació sobre la interrelació entre el 'com' i el 'què' en l'ensenyament de les llengües clàssiques, així com sobre algunes confusions que de vegades es donen entre l'un i l'altre. Partint de l'exposició -volgudament provocativa- d'alguns dels factors que en condicionen l'ensenyament avui dia (allò que anomenem 'els tres complexos de la Filologia Clàssica'), es planteja una reflexió al voltant de la finalitat de la nostra tasca docent, amb una reivindicació del mètode anomenat 'tradicional' en l'ensenyament de les llengües clàssiques. Finalment, es fa una reivindicació, també, del llatí i el grec com a factors estimuladors d'algunes competències que són absolutament necessàries i 'útils' per a l'alumnat del segle XXI.

PARAULES CLAU: Didàctica, llengües clàssiques, continguts, mètodes, competències.

\section{THE THREE COMPLEXES OF CLASSICAL PHILOLOGY}

\section{ABSTRACT}

The article is a brief dissertation on the interrelation between 'how' and 'what' in the teaching of classical languages, also regarding some of the misunderstandings sometimes occurring between one and the other. Based on the -purposefully provocative- presentation of some factors of influence in the teaching of Latin and Greek today (what are called 'the three complexes of classical philology'), a reflection upon the purpose of our teaching task, with a final vindication by Latin and Greek as stimulating factors in some of the competences that are

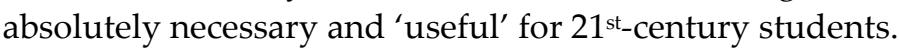

KEYWORDS: Didactics, classical languages, contents, methods, competences.

\section{INTRODUCCIÓ}

En les últimes dècades, les nostres matèries han estat objecte d'un intens debat pedagògic. Les publicacions, els debats, els simposis i les taules rodones sobre com ensenyar el llatí i el grec als alumnes del segle XXI han esdevingut una pràctica tan habitual que podem presumir, sense cap dubte, de ser un dels col-lectius docents que més i millor s'ha repensat, almenys pel que fa a l'àmbit de l'ensenyament secundari. Gràcies a aquest esforç ingent, avui dia multitud d'iniciatives, projectes, activitats, materials o pàgines web són a l'abast del professorat i dels alumnes que vulguin acostar-se a les llengües clàssiques d'una manera més innovadora. 
Molts d'aquests afanys s'han vist afavorits, però també condicionats, perquè la situació anterior, radicalment diferent, feia sentir amb molta força que la necessitat de renovació era urgent i indefugible, de manera que, en el fons, aquella ens ha servit de motor de canvi i d'espoleta per a l'actualització pedagògica. Però, precisament per la història particular que, pel bo i pel dolent, acumulen els nostres estudis, en alguns casos és possible adonar-se que, fins $\mathrm{i}$ tot avui dia, esforços lloables resten condicionats per determinats prejudicis i complexos que, segurament, encara arrosseguem del passat. Al nostre entendre, aquests 'complexos' són principalment tres: el complex d'innovació, el de matèria àrida i el d'inutilitat.

\section{COMPLEX D'INNOVACIÓ}

És innegable que, durant moltes dècades i amb comptades excepcions, l'estudi del llatí i el grec s'havia basat en un mètode d'ensenyament monòton i tediós. Molt sovint en mans del clergat, la docència dels clàssics es limitava amb freqüència a la memorització d'ensopides taules gramaticals i a la traducció mecànica de textos no especialment engrescadors, com la Guerra de les Gàl·lies, de Cèsar. La culpa d'aquesta situació segurament no era de ningú: les nostres matèries pouen en una tradició atàvica i, de fet, els orígens del seu ensenyament caldria anar-los a cercar al quadrivium medieval i a les escoles de gramàtica renaixentistes. A ningú ha d'estranyar, doncs, que tants segles de doctrina recepta ininterrompuda haguessin provocat l'encarcarament d'uns mètodes d'ensenyança que s'adaptaven cada cop menys i pitjor a les noves necessitats educatives (Archibald et al. 2014; Alcalde-Diosdado 2000).

La vinguda de pedagogies més modernes i, darrerament, de les noves tecnologies ja fa temps que van agreujar aquesta situació, fins al punt que, en alguns casos, ha produit el que aquí definim com a 'complex d'innovació', un complex, val a dir, que en la majoria de casos s'ha mostrat com a fecund i propositiu, i que en pocs anys ha capgirat les nostres matèries com un mitjó, bo i produint nous manuals d'ensenyament, incorporant tècniques pedagògiques innovadores, $\mathrm{o}$, fins $\mathrm{i}$ tot, reorientant per complet l'objecte d'estudi per desembocar en el que genèricament podem denominar mètodes 'actius' d'ensenyament (Coffee 2012; Hunt 2018).

\section{COMPLEX DE MATÈRIA ÀRIDA}

En certa manera derivat del punt anterior, podem parlar d'un segon complex, tant o fins i tot més sentit per part dels ensenyants de clàssiques: que les nostres són unes matèries àrides, massa complexes i difícils per a la majoria dels estudiants d'avui dia. És més, la seva excessiva aspror i inextricabilitat serien un dels motius principals de la seva poca acceptació i escassa matrícula entre l'alumnat. El corol-lari que se segueix d'acceptar aquest punt resulta obvi: cal abaixar, com sigui, el grau de dificultat de les nostres assignatures si no volem 
que les aules de clàssiques es vagin buidant com la cova del ciclop que, encegat, era incapaç de saber per on li fugien els ostatges mentre, a les palpentes, seguia grapejant l'esquena llanuda de les seves ovelles.

Aquesta voluntat d'atenuació ha pres normalment dos camins: per una part ha consistit (sovint de manera encertada) en la rebaixa -0 , directament, la supressió- d'alguns continguts (normalment gramaticals), així com en la seva substitució per altres temàtiques considerades més amenes (per regla general de cultura i civilització, o de literatura i mitologia), moltes de les quals havien estat bandejades de manera injusta en els temaris antics; per l'altra, en el que ara es coneix com a 'ludificació' ${ }^{1}$ dels ensenyaments, que en les nostres matèries ha tingut una acceptació notable $\mathrm{i}$ ha aconseguit substituir molts dels continguts tradicionals per activitats més lúdiques (menjars, vestits, tallers, músiques, representacions, sortides, etc.).

\section{COMPLEX D'INUTILITAT}

Un tercer complex que ens afecta com a col-lectiu es refereix al fet que els nostres són uns coneixements inútils. De fet, aquest és, amb tota seguretat, el que, de tots, portem més incorporat i més endins. Per fer-hi front hem adoptat, en general, dues postures, de vegades de manera simultània tot i ser antagòniques. D'una banda, solem dissertar sobre la "utilitat del que és inútil"2 i reivindiquem, amb raó, que no tot ha de servir per a algun fi en el sentit utilitarista del terme o que, més ben dit, precisament perquè hi ha coses que no serveixen per a res, hom pot arribar a plantejar-se preguntes més pregones i menys superficials que les que proporcionen els estudis merament pràctics. Reivindiquem per a les nostres matèries aquella bonica frase d'Agatha Christie: "No té la menor importància i, per això, resulta tan interessant".

D'altra banda, però, hem caigut sovint en la contradicció flagrant de córrer a enumerar un bon enfilall d'utilitats ben pràctiques per a les nostres matèries: hem d'estudiar llatí o grec perquè això ens permetrà millorar el nostre vocabulari, augmentar la nostra cultura, edificar una base per a l'aprenentatge d'altres llengües modernes, llegir els clàssics en llengua original, etc. Com hem argumentat en un altre lloc (Mut Arbós 2017), per bé que tots aquests raonaments són vàlids, no creiem que cap d'ells acabi constituint el motiu pel qual cap estudiant s'inscrigui a les nostres assignatures.

\section{FORTALESES I DEBILITATS}

Les respostes que com a collectiu ens hem donat per fer front a aquests 'complexos' han estat molt variades i riques en matisos i, en general, es pot dir

\footnotetext{
${ }^{1}$ Sempre preferible, pensem, a l'innecessari 'gamificació'.

${ }^{2}$ Per dir-ho amb les paraules de Nuccio Ordine i el seu imprescindible best-seller, La utilidad de lo inútil (Ordine 2013).
} 
que han resultat molt positives i han contribuit a millorar la situació d'una manera notable. Ara bé, cal alertar també d'alguns perills que, al nostre entendre, poden arrossegar determinades propostes. Així, observem com, en certes ocasions, la imperiosa necessitat d'innovació ens ha fet caure també en excessos modernitzadors $i$, potser, en un cert maniqueisme ('tot el mètode antic és dolent $\mathrm{i}$ tot el mètode nou és bo'). En aquest sentit, advertim contra la innovació acrítica, atès que aquesta no pot ser un fi en si mateixa. Com deia el professor Alberto Royo, se'ns ha d'exigir que 'ensenyem', no pas que 'innovem', i si, per fer-ho, emprem un mètode -o part d'un mètode- antic, doncs no passa res. ${ }^{3}$

En segon lloc, pensem que l'alleugeriment de continguts gramaticals i la ludificació de la pràctica a l'aula són, ben enteses, pràctiques necessàries i positives, però sempre que resti clar que els professors de clàssiques no només servim per a això. Hem de saber explicar, també, que rere l'activitat lúdica hi ha sempre un pòsit de coneixement valuós, que posseïm un saber profitós per als nostres alumnes i que el volem transmetre. A banda que fora fallaç, creiem, pensar que els nostres alumnes gaudiran necessàriament més fent un taller de màscares que, si es fa bé, analitzant amb rigor un passatge d'Homer o d'Ovidi. ${ }^{4}$

A l'últim, i com ja s'ha dit, per fer front al tercer complex, el de la inutilitat, molts col-legues han optat per un replantejament radical dels nostres estudis. Ha estat així com ha emergit amb gran força, sobretot en els darrers anys, l'ensenyança de les llengües clàssiques amb el mètode anomenat 'actiu', l'objectiu final del qual proposa tractar el llatí -i, encara que menys, també el grec- com si fossin llengües modernes. Aquesta nova visió del nostre objecte d'estudi ha suposat una petita revolució per a les nostres matèries, que s'han vist sacsejades des dels seus fonaments. Ara bé, també en aquest punt pensem que, un cop consolidat com a alternativa viable, fora bo deturar-se per analitzarne de manera crítica alguns aspectes.

\section{EL MÈTODE ‘ACTIU’}

Els arguments que els partidaris del mètode actiu han fet servir per defensar-ne l'adopció són diversos. I cal reconèixer que algunes de les fites que han aconseguit, com ara la reivindicació de l'estudi del vocabulari o la seqüenciació més natural i gradual dels continguts, són absolutament remarcables i

\footnotetext{
${ }^{3}$ En una recent entrevista a la revista Escuela (10/2/2017).

4 "No siempre se puede disfrutar aprendiendo. Lo que ocurre es que el premio es a medio o largo plazo, no inmediato. Y no siempre que uno aprende disfruta, es imposible. Piensa en un músico. Disfruta mucho durante el concierto. Pero antes de eso no todo es agradable. Practicar escalas es aburrido. Pero si quiero disfrutar y dar un concierto, ser expresivo y transmitir, necesito antes un trabajo imprescindible. No todo lo que se aprende en la escuela es divertido, pero no pasa nada porque no lo sea" (ibidem).
} 
encertades; tant que, de fet, pensem que s'haurien d'introduir i incorporar en tots els mètodes, també en el tradicional.

Un d'aquests arguments principals sosté que l'únic que fa el mètode actiu és recuperar la vella manera d'aprendre el llatí tal com l'aprenien els humanistes i les persones de cultura fins fa pocs segles, és a dir, parlant-lo en un 'context significatiu real'. Pensem, però, que aquesta argüició és en certa manera fal-laç, atès que aquell ensenyament es feia en un entorn on el llatí sí que era, en efecte, del tot necessari i indispensable com a llengua de cultura parlada i usada, i es produïa, per tant, en un entorn de significació totalment diferent. Avui dia, per molt que puguem simular escriure una carta a un amic en llatí, que puguem escoltar o cantar una cançó de moda en llatí o que puguem mantenir una conversa quotidiana en llatí, és impossible que l'alumne pugui sentir de veritat que es troba en un exercici real. El llatí no pot ser avui ensenyat com ho era durant el Renaixement precisament perquè el context de significació és tot un altre. Potser sap greu dir-ho, però voler ensenyar el llatí com si fos una segona llengua oblida el fet fonamental que, almenys en el món contemporani, no és una segona llengua.

Tot i que amb més dificultat, també ha estat aplicat un argument similar al grec, que els humanistes del Renaixement solien aprendre dels exiliats grecs arribats a Itàlia, els quals, per tant, transmetien el grec antic a través del sedàs del grec modern. De fet, s'ha arribat a proposar la pràctica substitució en els instituts del grec clàssic pel grec modern. ${ }^{5}$ Com argumentarem més endavant, opinem que aquest seria un error majúscul i, molt probablement, letal.

\section{QUÈ I COM}

Hom voldria fer notar, també, alguns contrasentits i confusions en el plantejament de determinats arguments per part dels partidaris del mètode actiu. Així, s'afirma sovint que aquesta és, només, una nova metodologia que intenta aconseguir a través de noves vies un domini igual o fins i tot superior del llatí i el grec; en altres paraules, un nou com per aconseguir bàsicament el mateix què. Tanmateix, de vegades advertim que el que s'acaba transformant és també, i de manera molt substancial, el què. Perquè el que proporciona, o almenys proporcionava, el mètode clàssic no era només un domini 'lingüístic' del llatí i el grec, sinó també un acostament rigorós i diligent al fet lingüístic i a la seva comprensió teòrica. Volem dir que si un alumne, en acabar els dos anys de batxillerat, és capaç d'expressar-se mínimament en llatí o d'entendre un redactat en grec, però en canvi no és capaç d'identificar un predicatiu, d'analitzar correctament un temps verbal, de deduir l'etimologia grecollatina d'un mot o de definir l'anàfora d'un pronom, el que li hem canviat a aquest alumne no és el com, sinó el què. I no entrem, per ara, a valorar si tots aquests

\footnotetext{
${ }^{5}$ Així ho fa, en un article a El País, Carlos Martínez Aguirre (2013), autor del polèmic, però cal reconèixer que deliciós, Confesiones de un filólogo clásico (Martínez Aguirre 2014).
} 
altres coneixements són necessaris o no; només diem que en molts casos el que s'haurà trastocat no és sols el mètode emprat, sinó el contingut mateix que els alumnes hauran après.

Si no es va amb compte, pot passar el mateix amb algunes ludificacions: la idea de convertir la classe tradicional en un taller més actiu és bona en si mateixa, però pot comportar que no només es canvii la manera com s'aprèn sinó també que el que s'aprèn no acabi essent exactament el mateix. Una contradicció que ens alerta d'aquest fet la trobem en la recent crida d'alguns col-lectius a la necessitat d'una reforma de la Selectivitat que tingui en compte "els nous mètodes d'ensenyament", ${ }^{6}$ car el que es demana als alumnes al final de l'etapa els afecta i els limita retrospectivament a l'hora de plantejar les seves classes. Però, si els mètodes actius sols suposen una nova metodologia, no haurien d'assolir, per bé que per altres camins, els mateixos continguts finals? No demostra aquest prec un poc incongruent que en realitat no parlem del com sinó del què?

\section{LLATÍ I GREC COM A SEGONES LLENGÜES}

Hi ha, a més, un altre factor molt important a tenir en compte per pensar-s'ho dos cops abans d'incorporar el mètode actiu a les nostres aules. Perquè cal pensar que, si convertim el llatí i el grec en llengües modernes, automàticament els enviem a 'competir' amb les altres llengües modernes, i això pot comportar que, caient en part en la trampa de l'utilitarisme, haguem d'assumir també algunes de les seves conseqüències indesitjables. Potser haurem d'acceptar, per exemple, que el llatí i el grec s'estudiïn de la mateixa manera que la majoria de la gent estudia les segones llengües, és a dir, amb presses, sense cap més voluntat que la purament utilitarista i sense esperar treure'n cap més benefici immediat que el de poder utilitzar aquella llengua el més aviat possible en contextos 'reals'.

Tots sabem, però, que el coneixement del món grecoromà i l'estudi de les seves llengües són, ben apresos, quelcom més que això; suposen una immersió reposada en tota una escala de valors que, a més, proporciona el domini d'uns continguts $\mathrm{i}$ unes destreses que han demostrat ser insubstituïbles per a la formació -no només humanística- dels alumnes de tots els temps i també, per no dir més, dels actuals. Per tant, reduir les llengües clàssiques a ser tan sols una segona llengua més seria, en certa manera, mutilar-les.

Però, a més, hi ha una objecció estrictament pràctica: si ho centrem tot a ensenyar el llatí i el grec perquè siguin una segona llengua més no correm el risc, ara sí, que la societat els bandegi per altres segones llengües que consideri

\footnotetext{
${ }^{6}$ Cf. el punt sisè de l'anomenat Manifiesto de Madrid 2017, elaborat pels participants en el simposi Métodos de enseñanza del latín y el griego, organitzat per la secció madrilenya de la SEEC (DD. AA. 2017). Vid., també, les veus recollides en el reportatge del diari Ara "No ha de fer por reformar la Selectivitat" (DD. AA. 2018).
} 
més 'útils'? Enviant les llengües clàssiques a competir en la 'roda' de les llengües modernes, no ens estarem exposant al fet que la gent les descarti per, ja que fan l'esforç, almenys estudiar una llengua moderna de veritat? Com hem dit, la majoria estudia segones llengües per obligació, per pura utilitat, perquè ho necessiten. De fet, la llengua més estudiada és la més 'útil': l'anglès. I, a partir d'aquí, el nombre d'estudiants va baixant segons el grau de percepció d'utilitat que l'idioma en qüestió tingui socialment: francès, alemany, rus, àrab, xinès, italià... On acabaria el llatí, ja no diguem el grec, en aquesta llista? Per no parlar del que passaria si es dugués a terme la proposta de substituir el grec clàssic pel modern: en aquest cas estem convençuts que suposaria l'estocada definitiva dels dos en pocs anys, car els alumnes -i els pares- no trigarien gens a demanar que el grec modern fos substituït pel francès, l'alemany o el rus. Dit d'una altra manera, creiem que cal reconèixer que, si fos per la seva utilitat real, ningú estudiaria ni llatí ni grec. I per tant, segurament el millor que podem fer és no jugar en aquesta 'lliga' i reivindicar que les nostres assignatures són importants perquè forneixen unes altres, $\mathrm{i}$ ben necessàries, competències.

En qualsevol cas, voldríem deixar clar que no estem en absolut en contra del mètode actiu; és més, com hem dit, pensem que ha aportat determinades innovacions a les nostres matèries que no sols no han de ser bandejades sinó que és urgent que s'incorporin als mètodes tradicionals. De fet, no discutim en absolut que amb el mètode actiu s'aprengui bé el llatí -fins i tot que s'aprengui millor el llatí-; ens limitem a objectar que, reorientant l'objecte d'estudi d'una manera tan radical, hem d'assumir que els coneixements i destreses adquirides seran, per força, diferents i que, conseqüentment, es deixaran d'aprendre altres continguts. El que discutim, per tant, és que puguem defensar socialment que els mètodes actius, per més engrescadors i estimulants que ens resultin als especialistes, s'ofereixin com una proposta necessària i viable en l'àmbit de l'ensenyament secundari.

\section{REIVINDICAR EL QUE SOM}

Arribats a aquest atzucac, quina resposta podem donar, com a col-lectiu, a tot plegat? Com hem dit, tots els que hem estudiat llengües clàssiques (per cert, amb el mètode tradicional) sabem que el llatí i el grec són molt més que simples llengües modernes. Sabem positivament que aporten un plus, una formació sòlida i insubstituible no només en el que avui anomenaríem 'competències' necessàries del currículum de secundària (lingüístiques, comunicatives, cíviques, artístiques, etc.) sinó també en l'establiment d'una visió humanista i comprensiva del món que ens envolta. A través del mirall dels antics, l'alumne pot descobrir millor qui és, d'on ve i qui vol ser (Fontán 2001; Alvar Ezquerra 2008).

Per a nosaltres, per tant, la discussió sobre si fora bo o no ensenyar les nostres matèries com es fa amb les llengües modernes en el fons no té a veure, 
malgrat que abans ho hem discutit, amb el context de significació o amb la percepció social d'utilitat, sinó que ateny a la finalitat mateixa dels nostres estudis, és a dir, a plantejar-nos el per a què pensem que són necessaris. Opinem que el llatí i el grec no són, per si mateixos, l'important en aquest viatge, almenys per a la gran majoria d'alumnes. De fet, en certa manera, no són sinó $l^{\prime}$ excusa que ens serveix per arribar a les competències i al tipus de formació de què parlàvem abans. Per tant, pensem que és aquest plus el que hem de reivindicar. Sense por de reconèixer que, en aquest sentit, el llatí i el grec, en efecte, no serveixen per a res. O més ben dit, posant de manifest que potser precisament perquè no serveixen per a res, resulta que serveixen per a tot, és a dir, que conformen un marc teòric prou allunyat de la realitat i els interessos de l'alumne al qual, just per això, poden fornir un camp ampli i fecund on desenvolupar les seves competències sense les presses de l'utilitarisme immediat.

\section{CONEIXEMENT PUR I APLICAT}

Volem deixar clar, també, que en cap moment estem afirmant que les llengües clàssiques no siguin importants per se. Només manifestem que la utilitat més immediata i positiva per als nostres alumnes no són les llengües clàssiques en si mateixes sinó el que es deriva del seu estudi. Ensenyem llatí i grec no perquè aquests siguin importants, sinó perquè les competències que s'aconsegueixen amb el seu estudi sí que ho són. Altre cop, l'important no és el què sinó el per a què.

Des d'aquest punt de vista, doncs, ens resulta evident que la revaloració i l'acceptació social dels nostres estudis no ens vindran pas de la circumstància de fer-los passar per una llengua moderna més. En certa manera, el nostre és un coneixement pur, no pas aplicat. Com ho són les matemàtiques en l'àmbit científic, les llengües clàssiques suposen una base -sovint força abstracta i teòrica- imprescindible per a ulteriors estudis lingüístics, culturals, filosòfics, artístics, històrics, literaris, jurídics, etc. No cal, doncs, patir cap complex d'innovació permanent, d'excessiva aridesa o d'inutilitat frustrant; el que cal és assumir i saber explicar bé què són i per a què serveixen les nostres matèries, sense complexos ni tergiversacions. A parer nostre, no sols és un error voler convertir el llatí i el grec en un coneixement 'aplicat' sinó que, de ben segur, el que el món actual ens demanarà cada cop més és, al contrari, fer-lo cada cop més 'pur', és a dir, més especulatiu i teòric i, per tant, més aprofitable des de molts i diversos camps del coneixement.

\section{CODA}

A l'últim, volem expressar el sentiment de disgust que ens provoquen certes opinions sobre els estudis clàssics tradicionals que resulta relativament habitual trobar-se aquí i allà. En efecte, gairebé ha acabat per esdevenir un lloc comú 
afirmar que els estudis clàssics tradicionals són inútils i antiquats o que la Filologia Clàssica és una "estafa" que no satisfà les expectatives dels estudiants (pretesament, dominar el llatí i el grec a la perfecció i ser capaços de llegir Tucídides o Tàcit sense cap ajut). ${ }^{7}$

Des d'aquesta tribuna, volem reivindicar que també som molts els que pensem que la Filologia Clàssica, amb el mètode tradicional amb què ens la van ensenyar, no sols ens ha estructurat la manera de pensar, de viure i de treballar, sinó que, en certa manera, ens ha ajudat a ser el que som. I els que pensem així ens demanem si cal bandejar amb tanta rapidesa una metodologia que ha permès això. Dit altrament: hauríem arribat al mateix punt i podríem fer ara l'anterior afirmació si la titulació de Filologia Clàssica s'hagués enfocat com una carrera de llengües modernes? Hom, amb franquesa, no entén ni comparteix aquesta fal-lera per proclamar que la manera com les nostres generacions havien estudiat és vella, avorrida, vana, i un bon enfilall de retrets més. No participem d'aquesta endemesa. Creiem que els nostres estudis, fins i tot així com ens els van ensenyar a nosaltres (ja no diguem si en renovéssim la metodologia per canviar el que efectivament és canviable), serveixen no sols per a l'Acadèmia sinó per a la vida i afirmem que constitueixen un nucli de sabers que cal, encara, reivindicar.

\section{BIBLIOGRAFIA}

AlCALDE-DiOSDADO, A. (2000), “La necesidad de renovación didáctica en las lenguas clásicas", Estudios Clásicos, 118, 95-131.

Alvar EzQuerra, A. (2008), "Las Humanidades en el s. XXI", Estudios Clásicos, 134, 105-120.

ARChibALD, E., BROCKLISS, W. i GNOZA, J. (eds.) (2014), Learning Latin and Greek from Antiquity to the Present, Cambridge, Cambridge University Press.

COFFEe, N. (2012), “Active Latin. Quo tendimus?", Classical World, 105, 255-269.

DD. AA. (2017), Sobre la enseñanza del Griego antiguo y el Latín en España hoy: fines, métodos, marco (Manifiesto de Madrid 2017. SEEC) [en línia]. Madrid: SEEC, 30 març 2017 [consulta: 29 juliol 2019]. Disponible a: <www.estudiosclasicos.org/wpcontent/uploads/3-Conclusiones-Manifiesto-de-Madrid-2017_-SEEC.pdf $>$.

DD. AA. (2018), “No ha de fer por reformar la Selectivitat", Ara, 8/06/2018.

FONTÁN, A. (2001), “El retorno a las humanidades”, Estudios Clásicos, 120, 7-16.

HunT, S. (2018), "Latin is not dead", dins Forward with Classics, Holmes-Henderson, A., Hunt, S. i Musié, M. (eds.), Londres, Bloomsbury, 89-108.

\footnotetext{
7 Així es fa no sols en un cèlebre article de Luigi Miraglia (1996) o en l'aspra i injusta La gran estafa de la Filología Clásica, una carta de Carlos Martínez Aguirre (2018) publicada originalment al seu blog i que ha tingut una gran difusió a la xarxa, sinó, fins i tot, per bé que amb un to menys displicent, en alguns dels més reeixits intents de reivindicar les llengües clàssiques, com els que es troben en els llibres de Wilfried Stroh (2007) o Andrea Marcolongo (2016).
} 
MARCOLONGO, A. (2016), La lingua geniale: 9 ragioni per amare il greco, Bari, Laterza (trad. de Lozoya, T. de i Rabasseda, J., La lengua de los dioses: nueve razones para amar el griego, Barcelona, Taurus, 2017).

MARTíneZ AGUIRRE, C. (2008), La gran estafa de la Filología Clásica [en línia]. Disponible a: <www.culturaclasica.com/?q=node/1904> [consulta: 29 juliol 2019].

MARTínEZ AguiRRE, C. (2013), “La extraña odisea del latín y el griego en Secundaria”, El País, 10/10/2013.

Martínez Aguirre, C. (2014), Confesiones de un filólogo clásico, Roquetas de Mar, Círculo Rojo.

MiRAGLIA, L. (1996), “Come (non) si insegna il latino”, Micromega, 5, 217-233.

Mut ARBÓs, J. (2017), “En torno a la didáctica de las lenguas clásicas: qué, cómo y para qué", Estudios Clásicos, 151, 157-177.

ORDINE, N. (2013), L'utilità dell'inutile: Manifesto, Milà, Bompiani (trad. de Bayod, J., La utilidad de lo inútil: Manifiesto, Barcelona, Acantilado, 2013).

STROH, W. (2007), Latein ist tot, es lebe Latein! Kleine Geschichte einer grossen Sprache, Berlín, List (trad. de Fernández, F., El latín ha muerto, jviva el latín! Breve historia de una gran lengua, Barcelona, Subsuelo, 2012). 